\title{
Review of international normatives for natural radioactivity determination in building materials
}

Eros Mossini, Elena Macerata, Marco Giola, Mario Mariani

\begin{abstract}
$\overline{\text { Abstract. Anthropogenic activities, such as high-altitude flights and living in buildings, have enhanced the public }}$ exposure to natural radiation. In particular, ${ }^{40} \mathrm{~K}$ and radionuclides belonging to ${ }^{232} \mathrm{Th}$ and ${ }^{238} \mathrm{U}$ decay chains are present even in building materials, and they may be considered as partially responsible for the effective dose coming from natural radioactivity. Scientists and governments have devoted great attention to the evaluation of the effects produced on the public by naturally occurring radionuclides. In this context, to evaluate the building materials acceptability, accurate and reliable methods for the measurement of the specific activity of natural radioactive isotopes in building materials have been developed. This paper aims to provide a clear and exhaustive review on natural radionuclide measurement procedures. Several standard national normatives (Dutch NEN 5697, Italian UNI 10797, Polish ITB 455), based on gamma spectrometry, have been considered and some critical issues were identified regarding the preparation and the radiometric measuring of the samples. Therefore, the direct measurement of ${ }^{238} \mathrm{U}$ and ${ }^{232} \mathrm{Th}$ by ICP-MS spectrometry as well as the extrapolation of the specific activities without waiting for secular equilibrium have been considered as two promising alternative approaches.
\end{abstract}

Key words: acceptability $\bullet$ building materials $\bullet$ gamma spectrometry $\bullet$ inductively coupled plasma mass spectrometry (ICP-MS) • naturally occurring radioactive material (NORM)

E. Mossini ${ }^{\bowtie}$, E. Macerata, M. Giola, M. Mariani Department of Energy,

Politecnico di Milano,

Piazza L. da Vinci 32, Milano, I-20133, Italy,

E-mail: eros.mossini@polimi.it

Received: 24 September 2014

Accepted: 20 May 2015

\section{Introduction}

Natural radioactivity is the main source of radiation which affects the human body [1]. Anthropogenic activities (e.g. high-altitude flights, mining and living in buildings) have increased the exposure to these sources [2]. In particular, the problem of natural radioactivity in buildings is of great interest since the building materials are of terrestrial origin and they consequently contain small, not negligible, amounts of naturally occurring radionuclides: the radioactive isotope of potassium, ${ }^{40} \mathrm{~K}$, and radionuclides belonging to the ${ }^{238} \mathrm{U}$ and ${ }^{232} \mathrm{Th}$ decay chains [3]. The building materials containing radionuclides occurring in the natural environment are called naturally occurring radioactive material (NORM) [4].

The raw materials extracted primarily for building purposes, granites (igneous rock) and the Italian tuff (pyroclastic rock) show very high radioactivity content [3]. For example, the mean specific activity of ${ }^{40} \mathrm{~K},{ }^{238} \mathrm{U}$ and ${ }^{232} \mathrm{Th}$ in red granite and volcanic tuff are, respectively, 1600, 150, $360 \mathrm{~Bq} / \mathrm{kg}$ and $1900,280,270 \mathrm{~Bq} / \mathrm{kg}$ [5], while the earth's crust averaged concentrations are, respectively, 400, 40 and $40 \mathrm{~Bq} / \mathrm{kg}$ [6].

Furthermore, the demand of large quantities of inexpensive raw materials for cost reduction and environmental sustainability purposes has led to the recycling of industrial wastes, thus enhancing the 
issue concerning public health. The classic example is phosphogypsum: it is a by-product generated from the large scale production of phosphoric acid and is widely used instead of natural gypsum, e.g., in plasters, cements, reinforced glasses and so on [3]. The phosphate rocks used to produce phosphoric acid contain high level of natural radionuclides (up to $1900 \mathrm{~Bq} / \mathrm{kg}$ of ${ }^{238} \mathrm{U}$ and $200 \mathrm{~Bq} / \mathrm{kg}$ of ${ }^{232} \mathrm{Th}$ ) [4]. Therefore, as a result of technological treatments, uranium and thorium series radionuclides are transferred in the final product as well as in the waste streams, that is, in phosphogypsum. By way of example, approx. $80 \%$ of the ${ }^{226} \mathrm{Ra}, 30 \%$ of ${ }^{232} \mathrm{Th}$ and $14 \%$ of ${ }^{238} \mathrm{U}$ formerly present in the phosphate rocks could be found in phosphogypsum, mainly resulting in a higher specific activity of ${ }^{226} \mathrm{Ra}$ of some order of magnitude with respect to the natural background [4]. Consequently, as shown in previous studies, phosphogypsum could appreciably increase the public radiation exposure in terms of gamma-ray doses and radon daughters concentrations [7]. Other examples of industrial by-products used as building materials that could increase the public exposure to radiations are: uranium and radium mine tailings, fluorogypsum from the production of hydrofluoric acid, red mud from the production of bauxite and coal ashes [3].

As a consequence of the concentrations of naturally occurring radionuclides in construction materials, the indoor radiation exposure of members of the public could become significant; therefore, preventive measures should be taken into account $[3,6]$. The radiation exposure due to environmental radioactivity could be divided into two categories, both to be taken into consideration for the public health issue (i) the external radiation exposure, which is engendered by the gamma emitting radionuclides, mainly belonging to the uranium decay chain segment starting with ${ }^{226} \mathrm{Ra}$; (ii) the internal exposure to alpha particles, which is due to the inhalation of radioactive inert gases radon, ${ }^{222} \mathrm{Rn}$ (a daughter product of ${ }^{226} \mathrm{Ra}$ ), marginally to thoron, ${ }^{220} \mathrm{Rn}$ (a daughter product of ${ }^{224} \mathrm{Ra}$ ), and their short-lived products deposited on the respiratory tract tissues $[6,8]$.

The growing attention to these aspects has led authorities in different countries to develop specific regulations to guarantee the public health $[6,8-12]$. A criterion for the use of such materials in buildings has been defined depending on the variation of the annual dose given to the public with respect to the natural background. According to the European Commission, this variation should be chosen on national basis, without exceeding a limiting value between 0.3 and $1 \mathrm{mSv} /$ year [6]. For example, Denmark, Netherland and Israel are countries characterized by low radioactivity background levels and therefore they acquired a stricter dose criterion [13]. In particular, governments in Denmark and Israel applied an excess dose of $0.3 \mathrm{mSv} / \mathrm{y}$. Whereas the Danish dose criterion refers only to gamma radiation, the Israeli criterion also includes internal exposure from radon [10].

Recently, an index, named $I_{e x t}$, has been introduced by European Commission to take into account the external radiation exposure, giving information coherent with the classical equivalent dose evaluation although it is not a direct measure of the absorbed dose given to the public [8]. It is defined as the sum of three different contributions (of ${ }^{40} \mathrm{~K}$, ${ }^{238} \mathrm{U}$ series and ${ }^{232} \mathrm{Th}$ series), as reported by Eq. (1):

$$
I_{\text {ext }}=\frac{A_{\mathrm{Ra}-226}}{a_{1}}+\frac{A_{\mathrm{Th}-232}}{a_{2}}+\frac{A_{\mathrm{K}-40}}{a_{3}}
$$

where $A_{i}$ denotes the measured specific activity of the radionuclide $i\left({ }^{226} \mathrm{Ra}\right.$ is the reference radionuclide for the ${ }^{238} \mathrm{U}$ series); $a_{i}$ is an index that is computed considering: (i) the maximum annual increment of public absorbed dose due to living in buildings (1 mSv/year); (ii) some geometrical factors such as the room dimensions; and (iii) some parameters typical of each source $\left({ }^{226} \mathrm{Ra},{ }^{232} \mathrm{Th}\right.$ and $\left.{ }^{40} \mathrm{~K}\right)$, such as: the annual exposure time, natural background, and exposure rate. For these coefficients, the European Commission sets the following values: $a_{1}=300$ $\mathrm{Bq} / \mathrm{kg} ; a_{2}=200 \mathrm{~Bq} / \mathrm{kg} ; a_{3}=3000 \mathrm{~Bq} / \mathrm{kg}$ [6]. To limit the public exposure to $0.3 \mathrm{mSv} / \mathrm{y}, I_{\text {ext }}$ must be less than 0.5 [6]. Anyway, the exposure is below $1 \mathrm{mSv} / \mathrm{y}$ if the index is less than unity.

A second index, named $I_{\text {int }}$, has been introduced to take into account the internal radiation exposure due to inhalation of radon gas and its decay products. $I_{\text {int }}$ is defined by a formula similar to Eq. (1) with a halved numerical value for the parameter $a_{1}$ [12].

To assess the possible radiological risks and the biological damages to human health coming from living in buildings, a reliable measurement of radioactivity levels of building materials is required. The most widespread method is gamma spectrometry, which, thanks to the high energy resolution and the counting efficiency, enables performing qualitative and quantitative analyses $[2,14,15]$. The data obtained from these analyses are essential for the development of standards and guidelines concerning the use and management of building materials.

The aim of this work is to perform a clear and exhaustive investigation on the measurement of radionuclides in building materials. A review of some eminent national standards is shown below in the next section: each operative step is described and the main criticalities are highlighted. Two valiant alternatives will be discussed in section 'Alternative approaches'.

\section{National standard review}

Over recent years, on behalf of the European Commission, within the framework of the "Construction Products Directive" 89/106/EEC, the Technical Committee CEN/TC 351 is preparing an unified European standard (CEN/TS 00351014) about the assessment of dangerous substances released from construction products that will affect all the European countries. The Dutch standardized method NEN 5697 "Radioactivity measurements - Determination of the natural radioactivity in stony building materials by means of semiconductor gamma-ray spectrometry" [16], written by Nederlands Normalisatie-instituut, has been assumed as the starting point for 
the composition of the unified European standard. In fact, in the Dutch standardized method, all the operative steps (sampling, sample preparation, radiometric counting and data elaboration) are widely taken into consideration and extensively described.

UNI 10797 "Natural radionuclides in building materials - High resolution gamma-ray spectrometry" [17] and ITB 455 "Natural radioactivity testing of building products" [18], written by the Instytut Techniki Budowlanej in replacement of the ITB 234 [19], are the standard procedures for the determination of natural radionuclides in building materials adopted in Italy and Poland, respectively. All the mentioned standardized methods exploit gamma spectroscopy to compute the specific activities. Next, the operating steps of interest (sampling and sample preparation, radiometric counting and data elaboration) are specifically described.

\section{Sampling and sample preparation}

The first essential step for a reliable measurement is sampling. The sample has to be representative and homogeneous $[14,15]$. According to NEN 5697, at least three random representative samples for each batch are required for a reliable sampling operation. In the particular case of cement concrete, three representative fresh concrete samples (taken as described in NEN 5955) have to be hardened for at least 1 day (as described in NEN 5965) before sample preparation. Neither the Italian nor the Polish standard takes account of the sampling step. The volume of the sample is important for an accurate analysis: greater amounts of sample will improve the representativeness, but at the same time the self-absorption within the sample will increase [15]. The Dutch and Italian normatives require samples of approx. $1 \mathrm{~L}$ for the analyses, while the Polish standard demands a sample consisting of $2.4 \mathrm{~L}$.

The achievement of suitable uniformity and homogeneity of the sample is the aim of the preparation step [15]. Both the Dutch and the Polish standards recommend grinding each sample to particles with a maximum size of $2 \mathrm{~mm}$ with a proper crushing apparatus, while the Italian normative suggests a maximum dimension of $1 \mathrm{~mm}$. Smaller size of the particles should imply greater bulk density and self-absorption [20]. After grinding, the powder has to be properly sieved. NEN 5697 standard suggests drying the ground material in oven at $103 \pm 2{ }^{\circ} \mathrm{C}$ until it reaches a constant weigh, that is, all the moisture evaporates from the sample. However, as this drying step is not mandatory, it can be omitted and must be replaced with an evaluation of the dry mass to take into account the fraction of water of the sample. On the contrary, the moisture elimination is mandatory for both the Italian and the Polish standards, by placing the sample in the oven at $100^{\circ} \mathrm{C}$ and $105^{\circ} \mathrm{C}$, respectively, until the sample reaches a constant weight. Although the drying step should be performed after the sample grinding in order to achieve the total elimination of moisture, the Italian normative suggests performing these two steps in inverse order, probably resulting in a partial drying of the sample. For all the standards, the homogenization step ends with the mixing of the powder obtained.

After the homogenization step, the sample has to be placed in a Marinelli beaker and sealed with a radon-tight lid. Only the Dutch standard reports a method to determine the radon tightness of the sample holder. Then the sample has to be stored for an appropriate length of time before analyses in order to let ${ }^{222} \mathrm{Rn}$ and ${ }^{220} \mathrm{Rn}$ to equilibrate with their daughters. In fact, throughout the preparation of the sample, the radon gas trapped in the building material pores is released, disturbing the equilibrium previously established among radon and its daughters. The achievement of the secular equilibrium is fundamental to perform a reliable analyses as will be discussed shortly. The selection of the storage time is dependent only on the half-life of ${ }^{222} \mathrm{Rn}$ (3.82 days [14]), while ${ }^{220} \mathrm{Rn}$ does not condition the choice because of its shorter half-life $(55.6 \mathrm{~s}$, [14]). Considering the ${ }^{222} \mathrm{Rn}$ half-life, a period of storage of at least 27 days is needed to re-establish the equilibrium with an approximation of less than $1 \%$ [21]. According to NEN 5697 and UNI 10797, the waiting time has to be 3 weeks and 20 days, respectively, while ITB 455 requests 14 days.

\section{Radiometric counting and data analyses}

Gamma spectrometry is the widespread technique used to detect natural radionuclides in environmental samples $[14,15]$. In particular, both the Dutch and the Italian standards establish using high-purity germanium (HPGe) detectors along with a multichannel analyser, while the Polish normative considers a scintillator detector coupled with a three-channel analyser, even though a modification has been suggested, replacing the three-channel with a multichannel analyser in order to allow the determination of more than three radionuclides [22]. In any case, the measurement apparatus has to be properly shielded with a lead cover in order to limit the environmental radioactivity impact $[14,15]$.

Among the natural radionuclides of interest for radiation protection issue, only ${ }^{40} \mathrm{~K}$ is directly measurable by gamma spectrometry thanks to its photopeak at $1460.83 \mathrm{keV}$, characterized by emission probability of $10.67 \%$ [14, 23].

${ }^{238} \mathrm{U}$ is hard to detect by gamma spectrometry due to the low energy and emission probability of the photopeaks of its first decay products. However, since in the ${ }^{238} \mathrm{U}$ series, approx. $98.5 \%$ of the radiological effects is engendered by ${ }^{226} \mathrm{Ra}$ and its progeny, the specific activity of ${ }^{238} \mathrm{U}$ could be assumed to be equal to that of ${ }^{226} \mathrm{Ra}$, neglecting its precursors [14]. ${ }^{226} \mathrm{Ra}$ could be directly measured by its photopeak at $186.1 \mathrm{keV}$, or indirectly taking into account ${ }^{222} \mathrm{Rn}$ decay products, for example, ${ }^{214} \mathrm{~Pb}$ (photopeak at $351.93 \mathrm{keV}$, with emission probability of $35.1 \%$ ) or ${ }^{214} \mathrm{Bi}(609.31 \mathrm{keV}, 44.6 \%)$. In this case, secular equilibrium between radon and its daughters must be ensured $[14,23]$. 
Gamma spectrometry is not sufficiently efficient to directly measure the photopeaks of ${ }^{232} \mathrm{Th}$, since they are characterized by low energy and emission probability. For this reason, the photopeaks of some of its decay products, ${ }^{228} \mathrm{Ac}(911.2 \mathrm{keV}, 25.8 \%),{ }^{212} \mathrm{~Pb}$ (238.63 keV, $43.3 \%)$ or ${ }^{208} \mathrm{Tl}(583.19 \mathrm{keV}, 30.4 \%)$ should be measured with the aim of evaluating the specific activity of ${ }^{232} \mathrm{Th}[14,23]$.

In particular, because of the choice of using a HPGe detector, NEN 5697 suggests considering the photopeak of ${ }^{214} \mathrm{~Pb}$ to estimate ${ }^{238} \mathrm{U}$ and the average of the specific activities of ${ }^{208} \mathrm{Tl}$ and ${ }^{228} \mathrm{Ac}$, for ${ }^{232} \mathrm{Th}$. Similarly, the Italian standard suggests several radionuclides of ${ }^{238} \mathrm{U}$ and ${ }^{232} \mathrm{Th}$ series for the analyses, but ${ }^{214} \mathrm{Bi}$ and ${ }^{212} \mathrm{~Pb}$ are considered to be the reference radionuclides. On the other hand, since the radioanalytical technique suggested by ITB 455 is the three channel gamma-ray spectrometry, in this case, the first channel $(1.26-1.65 \mathrm{MeV})$ is dedicated to ${ }^{40} \mathrm{~K}$, the second channel $(1.65-2.30 \mathrm{MeV})$ to ${ }^{238} \mathrm{U}$ by determining ${ }^{214} \mathrm{Bi}$ at natural equilibrium with ${ }^{222} \mathrm{Rn}$, the third channel $(2.30-2.85 \mathrm{MeV})$ to ${ }^{232} \mathrm{Th}$ following the gamma emission of ${ }^{208} \mathrm{Tl}$ at natural equilibrium with ${ }^{220} \mathrm{Rn}$.

The energy and counting efficiency calibrations are required [24, 25], but this step is described in details only in the Dutch standard. It is important to maintain the same experimental conditions of the calibration step, such as counting time, photopeaks, volume, geometry and position of the sample [15]. Counting efficiency for all the energy of interest has to be evaluated by means of suitable standardized calibration sources, characterized by a density near to that of the sample [15]. NEN 5697 demands to using four calibration sources characterized by different densities (between 700 and $1700 \mathrm{~kg} / \mathrm{m}^{3}$ ), while the Italian and the Polish standards require only one calibration source with density as close as possible to that of the sample. If some physicochemical properties of the sample under analysis (e.g. mass and bulk density) are different from the adopted calibration conditions, a correction for the self-absorption of gamma radiation should be applied [14]. Only the Polish normative introduces this self-absorption coefficient in order to consider the difference between the sample and the calibration source.

The contribution of the background has to be evaluated by measuring a blank with same volume and dimensions of the sample $[14,15]$. According to the Dutch standard, the blank of reference could be demineralized/distilled water and the blank spectrum has to be recorded with the same counting time of the sample. The Italian standard requires a solid blank of reference characterized by a matrix similar to that of the sample, but without radioactivity, and a counting time of at least $60000 \mathrm{~s}$ to achieve better counting statistics.

The counting time of the sample has to be chosen so as to reduce the statistical uncertainty to obtain a reliable and accurate measure. In particular, the counting time is governed by the radioactivity of the sample, detector-to-source distance and acceptable Poisson counting distribution uncertainty [15]. The Dutch standard demands counting times for the samples of at least $50000 \mathrm{~s}$, while according to UNI 10797, the sample has to be measured until the photopeaks areas are affected by an error below $10 \%$, or for at least $20000 \mathrm{~s}$. The Polish normative suggests performing, for each sample, 20 measurements of at least $2000 \mathrm{~s}$ each. Otherwise, it is also possible to increment the acquisition time.

Finally, with regard to the data analyses, the total net counts have to be determined from the measured spectra, considering the Compton continuum subtraction. Each specific activity has to be evaluated by taking into account the mass of the sample, blank measurement, and counting efficiency. As opposed to the Dutch and the Italian standards, ITB 455 includes a correction for the self-absorption in the data analyses. The standard deviation associated with each radionuclide and the lowest detectable limit have to be evaluated $[14,15]$.

\section{Alternative approaches}

By means of an accurate bibliographic research, two promising alternative procedure have been found and investigated. These different approaches appear promising in overcoming some of the critical aspects considered in national standards, mainly concerning sample preparation.

\section{Approximated measurement by extrapolation}

The wait for secular equilibrium achievement is a critical aspect that prolongs the time required for the analyses of the samples. A group of Italian researchers have developed an innovative method based on the extrapolation of the equilibrium activities of the radionuclides of the ${ }^{238} \mathrm{U}$ series, thanks to the measurement by gamma spectrometry of the same physical quantities within few days from the sample preparation [21].

According to this new method, after crushing to proper grain dimension, the material has to be placed in a Marinelli beaker and sealed to prevent further radon gas losses. The time evolution of the concentrations of ${ }^{222} \mathrm{Rn}$ and its daughters of interest for the measurement $\left({ }^{214} \mathrm{~Pb}\right.$ and $\left.{ }^{214} \mathrm{Bi}\right)$ can be described by differential equations, taking into account the production and consumption rate and the fraction of gas released during the grinding of the material. Analytical expression of the specific activity of ${ }^{226} \mathrm{Ra}$ at equilibrium is obtained by Laplace transform of the above-mentioned equations. In this work [21], the ${ }^{226} \mathrm{Ra}$ (for ${ }^{238} \mathrm{U}$ series) equilibrium concentration has been estimated introducing two radiometric measurements of ${ }^{214} \mathrm{~Pb}$ and ${ }^{214} \mathrm{Bi}$ performed during the first few days after sample preparation in those analytical expressions. This result has been compared with the one obtained following the standardized method after waiting for secular equilibrium achievement. The good agreement between the results of the two different approaches suggests the accuracy and reliability of the proposed alternative method. Whereas, concerning the evaluation of ${ }^{232} \mathrm{Th}$ series, 
the procedure of data extrapolation is not required because the ${ }^{220} \mathrm{Rn}$ losses do not excessively alter the ${ }^{212} \mathrm{~Pb}$ measurement since ${ }^{220} \mathrm{Rn}$ half-life is smaller.

\section{ICP-MS measurement}

The indirect measurement of uranium and thorium concentrations is another critical aspect characteristic of gamma spectrometry-based methods. A group of Japanese researchers has developed a method based on ICP-MS analyses to directly measure the concentration of ${ }^{238} \mathrm{U}$ and ${ }^{232} \mathrm{Th}$ in building materials, without relying on the achievement of secular equilibrium between radon and its daughters [26].

According to this method, the sample has to be ground to a powder, dried to constant weight in the oven at $110^{\circ} \mathrm{C}$ and then digested in Teflon vessels in a microwave unit using a mixture of nitric acid, perchloric acid and hydrofluoric acid. An advantage of this method is the reduction of the impact of certain variables, such as the grain dimension, the bulk density and, above all, the radon tightness of the sample holder. In this work [26], several building materials have been analyzed by ICP-MS and the results have been compared with those obtained by gamma spectrometry. A good agreement between the two approaches has been found. In particular, in case of sample with a good homogeneity, the ICP-MS technique seems to be a better choice than gamma spectrometry for $\mathrm{U}$ determination.

\section{Conclusions}

Great efforts have been made to develop standardized methods to unequivocally and reliably determine natural radioactivity in building materials $[14,15,20]$. In this paper, a comparative analysis between the Dutch [16], the Italian [17] and the Polish national standards [18] has been proposed to give a clear picture concerning the regulations currently in place for the determination of natural radionuclides in building materials.

The considered standards suggest performing the radiometric measurement with gamma spectrometry after suitable energy and efficiency calibration. Sampling is the most important step for a reliable and accurate analysis because all errors committed at this stage would propagate with no negligible effects. The sample preparation step includes: (i) preliminary crushing of the sample to a proper grain dimension; (ii) drying to constant weight to eliminate the total moisture; and finally (iii) homogenization of the powders and (iv) storage in a sealed Marinelli beaker for an adequate time interval to restore the secular equilibrium between ${ }^{222} \mathrm{Ra}$ and its daughters. Although conceptually similar, the three considered standards show few but important differences concerning the sample preparation. These differences can induce important modification in terms of grain dimension, bulk density and secular equilibrium achievement, with consequent no negligible effects on the measurement of the specific activities.
Because of these possible errors and uncertainties introduced by the preparation step described in the three considered standards, two alternative procedures have been reported to overcome some of the criticalities highlighted. Bruzzi et al. [21] approach aims to reduce the waiting time for secular equilibrium by extrapolating the specific activities of the radionuclides of interest by appropriate differential equations on the basis of two gamma spectrometric measurements performed within few days from the preparation of the sample. On the other hand, a Japanese proposal [26] is based on the direct measurement of ${ }^{238} \mathrm{U}$ and ${ }^{232} \mathrm{Th}$ concentrations by ICP-MS spectrometry, with the aim of reducing the time required for the activity determination as well as to eliminate the dependency of the results on the critical parameters previously mentioned, that is, grain dimension, bulk density and secular equilibrium achievement. Moreover, ICP-MS technique could enable achieving better sensibilities with respect to gamma spectrometry.

Nevertheless, in order to establish the most reliable and accurate procedure for the determination of natural radionuclides in building materials, a comparison by means of an extended experimental campaign on several representative samples is missing and therefore has to be performed.

\section{References}

1. UNSCEAR. (2000). Sources, effects and risks of ionizing radiation. United Nations Scientific Committee on the Effects of Atomic Radiation. Report to the General Assembly. New York: United Nations.

2. IAEA. (1990). The use of gamma-ray data to define the natural radiation environment. Vienna: International Atomic Energy Agency. (Technical Document no. 566).

3. NEA-OECD. (1979). Exposure to radiation from natural radioactivity in building materials. Report by Nuclear Energy Agency Group of Experts.

4. ARPANSA. (2005). Naturally-occurring radioactive materials (NORM) in Australia: issues for discussion. Report by Australian Radiation Protection and Nuclear Safety Agency.

5. Righi, S., \& Bruzzi, L. (2006). Natural radioactivity and radon exhalation in building materials used in Italian dwellings. J. Environ. Radioact., 88, 158-170. DOI: 10.1016/j.jenvrad.2006.01.009.

6. EC. (1999). Radiological protection principles concerning the natural radioactivity of building materials. Radiat. Prot., 112.

7. Laiche, T. P., \& Scott, L. M. (1991). A radiological evaluation of phosphogypsum. Health Phys., 60, 691-693.

8. STUK-Radiation and Nuclear Safety Authority. (2010). The radioactivity of building materials and ash. Guide ST 12.2. STUK.

9. Steger, F., \& Grün, K. (1999). Radioactivity in building materials önorm s 5200: a standard in Austria to limit natural radioactivity in building materials (revised and definite version). In Conference Proceeding of Radon in the Living Environment, 19-23 April 1999, Athens.

10. Standard Institute of Israeli. (2007). SI 5098, Content of natural radioactive elements in building products. Tel-Aviv, Israel. 
11. Vietnam National Radiation and Nuclear Safety. (1999). Decree No. 50.

12. National Standard of the People's Republic of China. (2001). GB 6566, Limits of radionuclides in building materials.

13. Kovler, K. (2008). Radiological constraints of using building materials and industrial by-products in construction. Constr. Build. Mater., 23, 253-264. DOI: 10.1016/j.conbuildmat.

14. ISO. (2007). Standard 18589-3: Measurement of the radioactivity in the environment - Soil - Part 3: Measurement of gamma-emitting radionuclides.

15. ASTM. (2009). Standard C 1402: Standard guide for high-resolution gamma-ray spectrometry of soil samples.

16. Nederlands Normalisatie Instituut. (2001). NEN 5697: Determination of the natural radioactivity in stony building materials by means of semiconductor gamma-ray spectrometry.

17. Ente Nazionale Italiano di Unificazione. (1999). UNI 10797: Natural radionuclides in building materials High resolution gamma-ray spectrometry.

18. Instytut Techniki Budowlanej. (2010). ITB 455: Natural radioactivity testing of raw materials and building materials. Warsaw.

19. Instytut Techniki Budowlanej. (1980). ITB 234: Guiding rules of investigating of the natural radioactivity of building raws and materials. Instruction. Warsaw.
20. ISO. (2007). Standard 18589-2: Measurement of the radioactivity in the environment - Soil - Part 3: Guidance for the selection of the sampling strategy, sampling and pre-treatment of samples.

21. Bruzzi, L., Baroni, M., Mele, R., \& Nanni, E. (1997). Proposal for a method of certification of natural radioactivity in building materials. J. Radiol. Prot., 17(2), 85-97. DOI: 10.1088/0952-4746/17/2/005.

22. Charewicz, W. A., Zebrowski, A., Walkowiak, W., \& Borek, B. (2000). A modified method for the determination of radioactive isotopes in building materials with multichannel gamma spectrometry. Nukleonika, 45, 243-247.

23. IAEA. (1989). Measurement of radionuclides in food and the environment. Vienna: International Atomic Energy Agency. (Technical Report Series 295).

24. ASTM. (2006). Standard D 7282: Standard practice for set-up, calibration, and quality control of instruments used for radioactivity measurements.

25. ASTM. (2010). Standard E 181: Standard test methods for detector calibration and analysis of radionuclides.

26. Hassan, N. M., Ishikawa, T., Hosoda, M., Sorimachi, A., Tokonami, S., Fukushi, M., \& Sahoo, S. K. (2010). Assessment of the natural radioactivity using two techniques for the measurement of radionuclide concentration in building materials used in Japan. J. Radioanal. Nucl. Chem., 283, 15-21. DOI: 10.1007/ s10967-009-0050-6. 